\title{
Reseña Histórica de Sonafluca La Fortuna de San Carlos
}

\author{
José Luis Torres R.*
}

\section{RESUMEN}

La década del 70 del siglo pasado fue muy rica en acontecimientos de carácter nacional e internacional de diversa naturaleza, luchas sociales en varios países de América Latina, crisis económica generada por el aumento abrupto en el precio del petróleo a nivel mundial, conflictos agrarios en diversas regiones del país, movimientos estudiantiles como el de ALCOA, etc. Este breve ensayo relata la experiencia personal con un grupo de campesinos de Naranjo deseosos de conseguir tierra para ofrecer un mejor futuro a sus familias. Se analiza la experiencia concreta de los campesinos como sujetos históricos de un nuevo proceso de incorporación al modelo del capitalismo agrario para insertarse en la cadena productiva de la mediana y pequeña propiedad en una comunidad de La Fortuna de San Carlos, denominada por los lugareños como Sonafluca. El intento de sistematizar la experiencia de un grupo de colonos es parcial, porque intenta explicar los problemas comunes de los campesinos cuando inician un proceso de asentamiento en los trópicos húmedos. Para ubicar a la comunidad en su contexto real, se realiza un breve resumen de los aspectos geográficos más sobresalientes.

Palabras clave: Campesino, asentamiento, pequeña propiedad, trópico húmedo, turismo, agricultura, ITCO, migración.

\section{ABSTRACT}

The 70's decade of the last century was very rich in national and international events of different nature, social fights in several countries of America Latina, economic crisis generated by the abrupt international increasing of the oil price, agrarian conflicts in diverse regions of the country, students' movements as the ALCOA, etc. This brief essay tells the personal experience of a countrymen group from Naranjo which wished to get land for offering a better future to their families. There is analyzed the concrete experience of the countrymen as historical subjects of a new process of incorporation to the agrarian capitalism model and get involved into the production chain of the medium and small property of the community in La Fortuna de San Carlos called Sonafluca by the same people of the country. Attempting to systematize the experience of these countrymen is partial since it tries to explain the common problems they have to undergo when beginning a new settlement in the humid tropics. To place this community in a real context, there is a brief summary of the most relevant geographic aspects.

Keywords: Countrymen, settlement, small property, humid tropic, tourism, agriculture, ITCO, migration.

Historiador y Abogado. Vicerrector Académico de la UNED, durante el periodo del 2003 al 2009. 


\section{Introducción}

La historia de una comunidad es una necesidad imperiosa de las personas que la habitan, pues constituye el elemento fundamental para entender el entorno vital en que se desenvuelven. Para el que intenta rescatar las vivencias de sus habitantes implica un esfuerzo por encontrar documentación oral y escrita para abordar la temática respectiva. En el caso de una comunidad tan joven como Sonafluca -33 años-, se intenta rescatar la vivencia particular del autor con respecto a las bases primigenias de la comunidad, tomando como referencia su experiencia con los parceleros que llegaron de Naranjo en 1976. Por tanto, no se pretende abarcar todos los aspectos de la vida cotidiana de la totalidad de los pobladores, por cuanto el asentamiento campesino se formó con otros labriegos que vinieron de Chachagua, Santa Clara y otros pueblos cercanos.

La pretensión ha sido fomentar la identidad local, rescatar la memoria histórica de aquellos "que no mandan, que no ejercen el poder," y sobre los cuales se escribe muy poco. Como bien lo indica ese gran historiador francés, Lucien Febvre "nunca he conocido, y aún no conozco, más que un medio para comprender bien, para situar bien la historia grande.
Ese medio consiste en poseer a fondo, en todo su desarrollo, la historia de una región de una provincia. ${ }^{1}$ "

Se incluyen en este breve ensayo algunos aspectos geográficos generales de la región norte y en particular de Sonafluca, con el fin de que sea un instrumento que sea aprovechado por los educadores y estudiantes para conocer mejor su comunidad.

Con motivo del 33 aniversario del Asentamiento Campesino Sonafluca, en el cual se inauguró el vado sobre el río Fortuna y el asfaltado de dos kilómetros de carretera dentro del pueblo, se invitó a diversas instituciones públicas del Cantón de San Carlos para inaugurar tales obras. Fue muy interesante notar, en todos los oradores, el reconocimiento a la calidad humana de las gentes, por el esfuerzo realizado en estos treinta y tres años. Destacaban el marcado interés por la educación, hay una Escuela desde su fundación y un Colegio de Secundaria de reciente creación, así como la laboriosidad en los campos, pues es frecuente encontrar empacadoras de tubérculos, plantaciones de papaya, plátano, viveros, módulos lecheros, etc.

Esperamos que este primer ensayo contribuya a estimular a los educadores y a los habitantes del lugar, que quieran desentrañar las particularidades de esta comunidad. Agradecemos

1. Enríquez Solano, Francisco. Pasado y presente del Cantón de Goicoechea. EUNED. 2004, pág. xiv. 
a todas las personas que colaboraron con el aporte de diversa información, al Lic. Erick Rodríguez Corrales del Centro de Planificación y Programación Institucional de la Universidad Estatal a Distancia, a mi hermana Sonia Torres, a Eliseo Ovares por aportar datos interesantes de Sonafluca.

\section{Descripción geográfica de Sonafluca}

En un ensayo sobre la historia parcial de la comunidad de Sonafluca, de La Fortuna de San Carlos, se considera necesario indicar los aspectos geográficos característicos del lugar. De esta manera, constituye un marco de referencia para analizar la relación entre el entorno geográfico y la experiencia vivida por los habitantes.

\section{Situación y límites}

La comunidad de Sonafluca pertenece al distrito La Fortuna del Cantón de San Carlos, las coordenadas geográficas medias del cantón de San Carlos están dadas por $10^{\circ} 37^{\prime} 02^{\prime \prime}$ latitud norte y $84^{\circ} 30^{\prime} 53^{\prime \prime}$ longitud oeste. En Ley
No. 17, del 26 de setiembre de 1911 San Carlos se convirtió en el cantón décimo de la provincia de Alajuela, con cuatro distritos. San Carlos procede del cantón de Naranjo, establecido este último en decreto ejecutivo No. 2 del 9 de marzo de 1886.

La altitud media es de 253 metros sobre el nivel del mar; la superficie del distrito La Fortuna es de $225 \mathrm{~km}$ cuadrados. La comunidad de Sonafluca está rodeada por los distritos de Florencia, Fortuna, Monterrey, Chachagua y la comunidad de Los Ángeles.

Es importante acotar que La Fortuna, a inicios de la década del 70 del siglo pasado, era un pueblo rural pequeño y con una economía basada en la ganadería y agricultura, que experimentó un importante cambio a partir de la década de 1990 para convertirse en una de las regiones turísticas más importantes del país. El paisaje rural con campesinos y ganaderos se ha visto acompañado por empresarios, comerciantes, y servicios dedicados a la actividad turística. 


\section{GRÁFICO N. ${ }^{\circ} 1$}

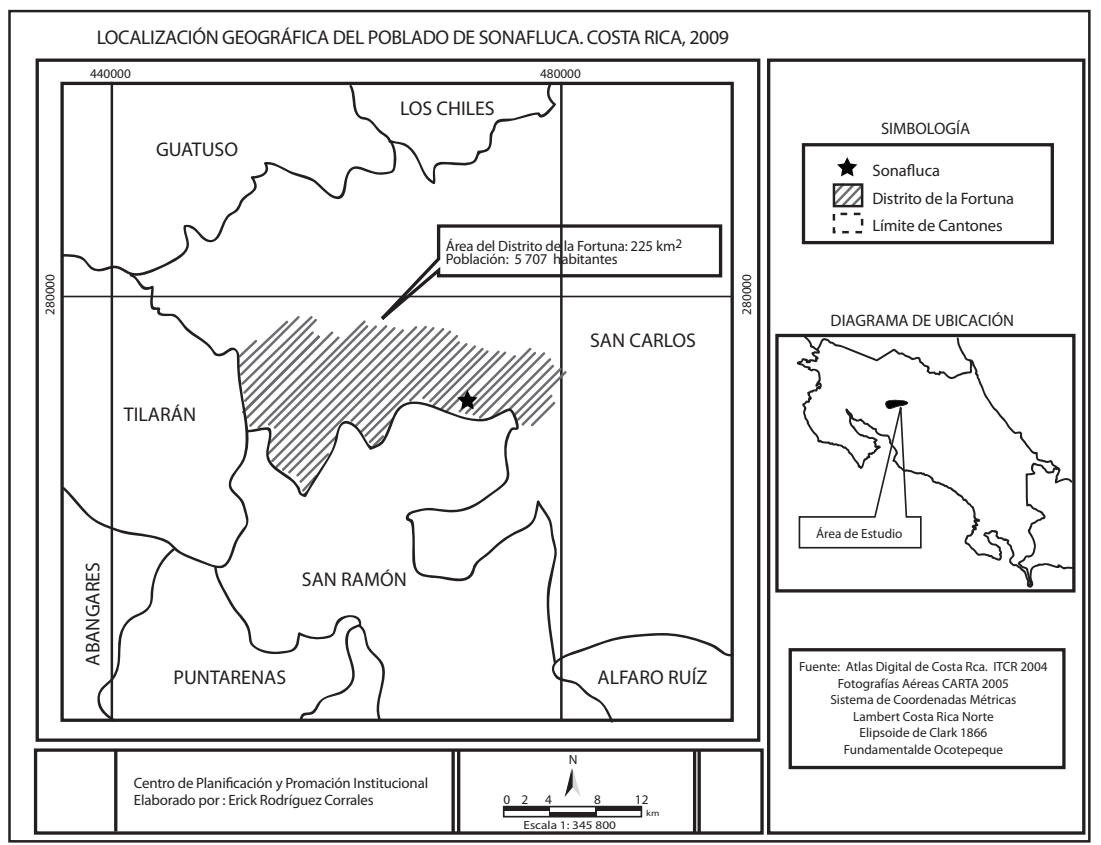

\section{Hidrografía}

El sistema fluvial del cantón de San Carlos, corresponde a la sub vertiente Norte de la vertiente del Caribe, la cual está comprendida por las cuencas de los ríos San Carlos, Pocosol, Frío, Sarapiquí y Cureña.

La primera es drenada por el río San Carlos, que nace de la unión de los ríos Jabillos y Peje; el primero se origina en la confluencia de los ríos La Tigra, La Esperanza, San Lorenzo y Balsa y el segundo de los ríos
La Vieja y Ron Ron, que nace en el volcán Porvenir. Afluentes del río San Carlos son Platanar, que nace en el volcán del mismo nombre; Peñas Blancas, que se origina en la Sierra Minera de Tilarán; Arenal, que nace en la laguna del mismo nombre, Tres Amigos, que se origina de la confluencia de los ríos Guayabo y Negritos, y los caños Hidalgo y el Grande al que se le unen los ríos Aguas Zarcas y Sahíno, los cuales nacen en fila Chocosuela, y los volcanes Platanar y Porvenir. 
La comunidad de Sonafluca está rodeada al norte por el río Fortuna, sobre el cual recientemente se ha construido un vado con ayuda de la Municipalidad de San Carlos y de la propia comunidad. Este río ha sido un factor de desarrollo turístico importante tanto en La Fortuna como en Sonafluca por la belleza de su serpenteo geográfico. La Asociación de Desarrollo comunal de dicho distrito ha venido desarrollando un proyecto turístico sobre la catarata de este río cerca de La Fortuna, que ha sido visitada por miles de turistas nacionales y extranjeros. Al sur, la rodea el río Burrito el cual, en época de mucha lluvia, se convierte en un río con un caudal importante, que lleva sus aguas al río Peñas Blancas, afluente del río San Carlos.

\section{Geología}

El cantón de San Carlos está constituido geológicamente por materiales de los períodos Terciario y Cuaternario; son las rocas volcánicas del Cuaternario las que predominan en la región. De los materiales del período Cuaternario se localizan rocas de origen volcánico y sedimentario. Las volcánicas son de las épocas Pleistoceno y Holoceno; la primera pertenece a lahares sin diferenciar, que cubren la mayor superficie del cantón, encontrándose lahares finos. En la parte norte de la región las rocas volcánicas del Holoceno están representadas por edificios volcánicos recientes y actuales, y piroclastos asociados, ubicados al sureste del cantón, lo mismo que en la ladera oeste del volcán Arenal, y por materiales volcánicos, tales como lavas, tobas y piroclastos, situados en la ladera este del volcán Arenal y del cerro Chato. Las rocas sedimentarias de la época antes citada corresponden a depósitos Fluviales y Coluviales, localizados en las márgenes del río San Carlos, curso inferior de los ríos Arenal, Peñas Blancas y Tres Amigos, lo mismo en la margen este del curso medio e inferior del río Pocosol, así como en la margen sur del río San Juan y un pequeño sector del curso inferior del río Infiernito.

\section{Geomorfología}

El cantón de San Carlos presenta dos unidades geomórficas, denominadas forma de sedimentación aluvial y de origen volcánico. La unidad de sedimentación aluvial se divide en siete subunidades, llamadas llanuras Altas Vigas en Proceso de Erosión, llanura Aluvial de San Carlos y el Caribe, llanuras Bajas Recientes, abanico Aluvial de Santa Clara, abanico Aluvial de Aguas Zarcas, abanico Aluvial de los ríos Cuarto y Sarapiquí, y Pantano Permanente o Temporal.

Sonafluca se ubica en la subunidad Llanura Aluvial de San Carlos y el Caribe; se localiza en la región comprendida por las villas Fortuna 
y Boca de Arenal, los poblados Los Ángeles, San Pedro, San Juan, Los Llanos Muelles San Carlos, La Guaria y al norte de Vaca Blanca, así como en las márgenes del río San Carlos y las del curso medio e inferior del río Tres Amigos; también en el sector aledaño a los poblados Bellavista, Veracruz y Palmar, esta subunidad representa una superficie plana que en algunos sitios es ligeramente ondulada, y está paralela a la sierra Volcánica Central. ${ }^{2}$

\section{Clima Región Norte ${ }^{3}$}

\section{Lluvia}

En la Zona Norte, los mínimos de precipitación se dan desde enero hasta abril, como lo muestra el Gráfico 20 de la estación meteorológica de San Jorge en Los Chiles, ubicada a $55 \mathrm{~m}$ de altitud y datos de lluvia de S. Vicente situada en Ciudad Quesada a $1450 \mathrm{~m}$ de altitud. Se observa que mientras el promedio en las llanuras (San Jorge) es de $2612 \mathrm{~mm}$, en los lugares montañosos (S. Vicente), este valor es mayor a $3992 \mathrm{~mm}$; en ambas estaciones se da una disminución de las lluvias entre febrero y marzo, pero fácilmente se observa que la disminución es más acentuada en las llanuras de la Zona Norte (San Jorge, Los Chiles).

\section{Temperatura}

El comportamiento de la temperatura en la Zona Norte de nuestro país, depende de muchos factores y uno de ellos es la altitud, a $1450 \mathrm{~m}$ en el área de montaña (San Vicente de Ciudad Quesada) los promedios de temperatura $\left(17^{\circ} \mathrm{C}\right)$ son claramente más bajos que los de Santa Clara de San Carlos, a $170 \mathrm{~m}$ donde los valores medios de temperatura rondan los $25.4^{\circ} \mathrm{C}$. Estos valores son bastante alejados unos de otros a lo largo del año.

Coinciden los meses de abril y mayo como los más cálidos, mientras que los primeros meses del año son los más fríos, con temperaturas mínimas que fácilmente alcanzan menos de $13^{\circ} \mathrm{C}$ en las partes altas de la región.

\section{Viento}

La estación de Santa Clara de San Carlos, -muy cerca de Sonafluca-, a $170 \mathrm{~m}$ de altitud, reporta predominio de componente sur a lo largo del año, con velocidades promedio de 5,5 $\mathrm{km} / \mathrm{h}$; pero hay que recordar que en

2. Chinchilla V E. Atlas Cantonal de Costa Rica. Instituto de Fomento y Asesoría Municipal. (IFAM), San José, Costa Rica, 1987.

3. Alvarado Salas, Ronulfo. Regiones y Cantones de Costa Rica. IFAM. Dirección de Gestión Municipal. San José, 2003, pág.7; define una región de la siguiente manera: "es el producto de un conjunto de relaciones sociales, históricas, económicas y administrativas que adquieren características particulares en un determinado espacio geográfico". 
SAN JORGE, Los Chiles (1979-2000)

S. VICENTE, C. Quesada (1972-2000)

Promedios de lluvia mensual

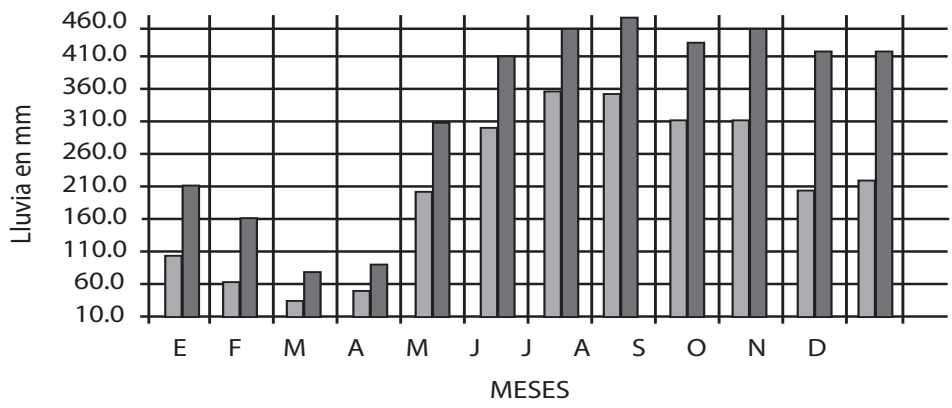

$\square$ S. Jorge $\square$ S. Vicente

Fuente: Instituto Meteorológico Nacional de Costa Rica. 2009, www.imn.ac.cr/educacion/climacv/ zonanorte.html

algunas ocasiones el componente Norte o noreste es la principal herramienta para provocar ascenso mecánico de las masas de aire para la generación de lluvias en estas regiones.

\section{Humedad Relativa}

En el Gráfico 3, se presentan los datos de Humedad Relativa de Santa Clara. Se puede observar que la mayor parte del año los valores se mantienen en rangos próximos al
$80 \%$, que hay un descenso del porcentaje de Humedad Relativa durante los primeros meses del año, y que lo mismo sucede en Coopelesca (la estación meteorológica ubicada a $650 \mathrm{~m}$ de altitud).

Cabe destacar que esta merma en la Humedad Relativa coincide con los meses de menos precipitación en la zona Norte de nuestro país.

En el gráfico siguiente se puede inferir que la zona norte es la región del país de mayores precipitaciones. 
SANTA CLARA (1983-2000)

Promedios de Humendad Relativa

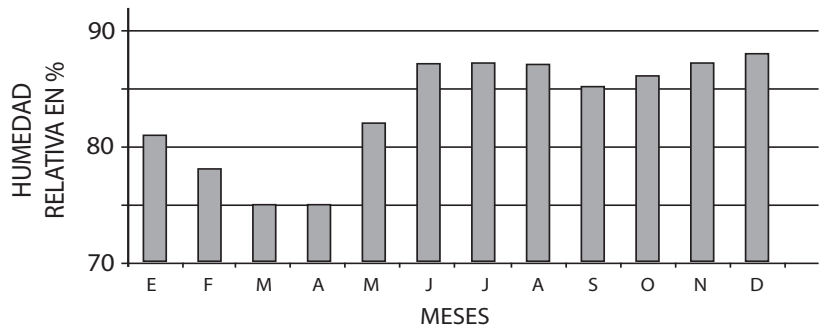

Fuente: Instituto Meteorológico Nacional de Costa Rica. 2009. www.imn.ac.cr/educacion/climacv/ promedios \% 20 anuales.phg

Este factor permite que se desarrollen una serie de actividades agropecuarias, industriales y también para el ecoturismo. El embalse de Arenal constituye un elemento importante para la producción de energía hidroeléctrica. En muy pocas ocasiones ha alcanzado los mínimos necesarios para alimentar las plantas hidroeléctricas de Arenal, Sandillal y Corobicí.

\section{Uso del suelo}

El uso del suelo en esta comunidad se basa en el Atlas Digital de Costa Rica, en sus versiones 2000 y 2004, por el Instituto Tecnológico de Costa Rica, y muestra que en este sector de La Fortuna y alrededores predominan las zonas dedicadas al pastoreo (pastos), bosque natural $\mathrm{y}$, en menor porcentaje, el bosque venido y el bosque secundario. No se distinguen zonas exclusivas para el cultivo, es decir, grandes extensiones dedicadas a monocultivo, como es característico en otras zonas del país. ${ }^{4}$

Las fotografías aéreas tomadas por el proyecto Carta - 2005, (NASA/ CONARE), en las que se muestra el uso que se hace del suelo en Sonafluca, nos señalan áreas de pastos, cultivos de plátano, yuca, papaya, viveros. El bosque natural y secundario fue destruido para el desarrollo de cultivos de subsistencia

4. Berrocal Vargas, Milena. Análisis y evaluación de la vulnerabilidad de la población de La Fortuna de San Carlos a la actividad del Volcán Arenal- Costa Rica. Tesis. Universidad de Girona, 2008, pág. 164. 
y exportación, dado que el objetivo del ITCO, hoy IDA, fue establecer un asentamiento campesino para el desarrollo de la agricultura propia de la región.

\section{Actividad turística de Sonafluca}

Como una posición refleja del crecimiento poblacional y la actividad turística de La Fortuna, Sonafluca se ha visto beneficiada en alguna medida con este desarrollo. El análisis de los datos poblacionales de los Censos de Población de 1963, 1973, 1984, 2000, y proyecciones del 2006 y 2007, elaborados por el Instituto de Estadística y Censos (INEC), demuestra un importante crecimiento poblacional en relación con la inversión económica del sector turístico en la zona de La Fortuna.

Si bien el crecimiento demográfico de La Fortuna está íntimamente ligado al desarrollo de la actividad turística en la zona, esta no se dio inmediatamente después de la erupción del Volcán Arenal en 1968. Pasaron casi veinte años para que la actividad turística se viera como una forma de vida, sustituyendo progresivamente a la ganadería. Durante la década de
1960-1970, el acceso a la zona seguía siendo difícil a falta de una carretera con las condiciones adecuadas no solo hacia La Fortuna sino también hasta el volcán. La curiosidad por visitar el volcán nació a raíz de la espectacularidad de sus erupciones tipo estromboliano entre 1986- 1993, y de la creación del Parque Nacional Volcán Arenal en 1991.5

El Instituto Costarricense de Turismo, en su informe de 1996, indicaba que el 36,4 \% del Turismo que ingresó a Costa Rica visitó el Volcán Arenal, es decir, 232.562 personas. Para el 2006 La Fortuna de San Carlos había pasado a tener 11785 habitantes, 7309 más que en 1984, un crecimiento mayor que la propia cabecera del Cantón. ${ }^{6}$

Para el caso de Sonafluca, hubo una relación directa con el crecimiento del turismo en La Fortuna, pues dada la cercanía se tomó La Casona, antigua casa de habitación de don Quico Rodríguez, uno de los primeros pobladores de esta comunidad y quien desarrolló una hacienda ganadera, antes de que se conformara como el Asentamiento de Sonafluca. La Casona se utiliza hoy como lugar de recreo para los turistas que visitan

\footnotetext{
5. Berrocal Vargas, Milena. Op. Cit; pág. 179.

6. Ibid., pàg. 182.
} 
la Fortuna, pues les permite conocer las costumbres y forma de vida de una comunidad campesina. El río Fortuna bordea La Casona y es punto de entrada obligatorio a la comunidad. El turismo ha beneficiado mucho pues se ha constituido en fuente de empleo para muchos de los pobladores, en diversas tareas que genera así como en la rama de la construcción de hoteles y cabinas.

\section{Antecedentes históricos}

La década del 70 del siglo pasado fue muy rica en acontecimientos sociales, políticos y económicos. Un ejemplo de ello fue la lucha contra ALCOA, empresa norteamericana que logró una concesión por parte de la Asamblea Legislativa en el Gobierno de José J. Trejos Fernández. Para explotar bauxita en Pérez Zeledón; esto generó un cúmulo de protestas estudiantiles que llevó luego a la emergencia de varios partidos políticos de izquierda en el país. En el sector agrario, hubo varios conflictos por ocupación de tierras en precario, y uno de los más conocidos es el Asentamiento El Jobo, en La Cruz, Guanacaste; también se dieron enfrentamientos en la zona sur, en la Vaca y la Vaquita, en Sarapiquí, Limón, etc.

El contexto latinoamericano era propicio también para el desarrollo de ideas sociales que propugnaran mayores niveles de justicia social en las áreas urbanas y principalmente rurales. Fue una década de muchas luchas agrarias en diversas regiones del país.

Los sectores campesinos se sentían marginados del proceso de apropiación de la tierra, dado que el fenómeno de expansión de la actividad ganadera había abierto frentes de colonización para desarrollar la ganadería extensiva en regiones que se consideraban de bosque primario, principalmente en la región de San Carlos, Sarapiquí y zona sur. También recordemos que el fenómeno del aumento demográfico de los años sesenta, el más alto en la historia del país, estaba surtiendo efectos; muchas familias necesitaban techo y trabajo.

Nuestro país había sufrido cambios importantes en su estructura social y económica, a partir de la Guerra Civil de 1948, con el fin de impulsar un modelo de Estado caracterizado por la intervención en la economía y lograr así un mayor reparto de la riqueza y la equidad social. Esta pretensión había favorecido más a una clase media emergente y no así al campesinado. El surgimiento de una clase media formada por profesionales del sector público (maestros, profesores universitarios, empleados públicos), aunado al crecimiento de un sector de la pequeña y mediana propiedad, habían contribuido a forjar una Costa Rica diferente, donde la educación y la salud constituían pilares en el nuevo Estado benefactor. El proyecto político impulsado por Figueres, "constituía 
un plan integralmente concebido donde lo económico iba de la mano con lo social y lo político... Tal estrategia integraba propuestas para el desarrollo capitalista, por medio de la modernización de la infraestructura material de la economía y la diversidad productiva. Asimismo contenía propuestas orientadas a atenuar las asimetrías sociales y lograr una distribución del ingreso y la riqueza más igualitaria, como también, y finalmente, era una propuesta que buscaba consolidar un sistema de democracia representati$v a$, mucho más estable, confiable y transparente del que rigió durante la dominación oligárquica" ${ }^{\text {"7 }}$.

El sector agrario vinculado a los jornaleros y campesinos pequeños y medianos, venía siendo golpeado por la crisis petrolera del año 73 , el fenómeno de expansión de la ganadería extensiva, la desaparición del minifundio, los bajos salarios y otros factores estructurales de la economía costarricense, tales como las mejoras tecnológicas en el agro, conocida como la revolución verde, que fueron desplazando mano de obra de los cafetales.

En el caso del Cantón de Naranjo, podíamos encontrar una apropiación de la tierra por parte de grandes, medianos y pequeños propietarios que vivían las fluctuaciones del precio del café en el mercado internacional.
Por tratarse de un Cantón monocultivista, los efectos de los precios del grano de oro se hacían sentir en forma inmediata en sentido positivo o negativo. Los trabajadores del café, denominados en nuestro medio como jornaleros o peones, sufrían los efectos de este fenómeno y del creciente costo de la vida. Para muchos de ellos, la situación era insostenible porque no tenían horizontes claros para poderle dar a sus hijos una educación secundaria y universitaria.

El modelo económico del Estado intervencionista empieza a tener sus contradicciones por cuanto se nota un crecimiento de la burocracia del sector público pero se deja de lado al sector más débil de la cadena productiva: al sector campesino. Es en la década de los años ochenta, cuando las políticas neoliberales empiezan a tener mayores efectos, por la sobrecarga en la actividad de gobierno por la expansión política y el desarrollo de las actividades estatales. ${ }^{8}$ Para paliar estos efectos, el sector de medianos y pequeños productores de café, -en la región Alajuela -San Ramón-, habían logrado conformar Cooperativas de café, para defenderse de los bajos precios del café y evitar a los beneficiadores que se llevaban la mayor parte de la ganancia con el proceso

7. Rodríguez Vega, Eugenio. Costa Rica en el siglo XX. Tomo II. Vargas, Solís, Luis P. La Economía. San José, EUNED. 2004, pág. 341. 
industrial de procesamiento del café y su exportación. ${ }^{9}$

La producción de café en Naranjo ha sido históricamente importante. Ya desde la primera mitad del siglo XIX, se había iniciado el proceso de colonización de esta región, por parte de don Judas Tadeo Corrales y los hermanos Mora. ${ }^{10}$

El café atrajo hacia esta región un grupo importante de colonizadores que aprovechando la existencia de tierras baldías, vendieron sus herencias en Santo Domingo, San José, Heredia y alrededores para venir a esta región y asentarse con sus familias. Muchas de las familias actuales de Naranjo descienden de estos primeros colonizadores, generando un proceso de apropiación de la tierra, y por ende el desarrollo incipiente del capitalismo agrario con la privatización de la tierra. Con el crecimiento demográfico y también con la expansión de la frontera agrícola hacia otras áreas de colonización, como San Carlos, San Isidro de El General, Guatuso, Upala, Los Chiles, San Dimas -La Cruz- Guanacaste, Guápiles, etc, se fueron dando diversas oleadas migratorias hacia estas regiones por parte de jornaleros y medianos y pequeños propietarios de tierra que consideraban que Naranjo no cumplía sus expectativas futuras de desarrollo personal y familiar. Como bien lo señala el Instituto Nacional de Estadísticas y Censos, Costa Rica, en los años sesenta del siglo pasado, experimentó las tasas de población más altas del mundo. Esto se expresó en la década siguiente en una presión fuerte por la tierra por parte de los campesinos.

"La historia de la demografia costarricense es la típica de otros países latinoamericanos aunque algo más acelerada y adelantada. Hacia 1960 el país tenía una de las tasas vegetativas de las poblaciones más altas del mundo, cercana al $4 \%$ anual, producto de una mortalidad relativamente baja y una fecundidad excepcionalmente alta. En esa época se inicia una rápida caida de la fecundidad, que pasa de 7,3 hijos por mujer a 3,8 hijos en 1975. Luego de un paréntesis de alrededor de una década, la baja continúa y en el año 2001 el país alcanza la fecundidad de reemplazo, convirtiéndose en el primero en Latinoamérica, después de Cuba en hacerlo. Al mismo tiempo, su esperanza de vida (81,4 años en mujeres y 76,9 años en hombres en 2005) es una de las más altas del continente,

8. Para ampliar este tema véase, el texto de Michel Crozier francés, Samuel J. Huntington, estadounidense, y Joji Watanuki, japonés, La Crisis de la Democracia. http// www.crisis of democrazy

9. Mora, Johnny. La vía cooperativa de desarrollo del agro. El caso de Coopronaranjo R.L.EUNA, 2007.

10. Al respecto véase Torres, José Luis. Naranjo y su historia. EUNED. San José, 2007. 
superior incluso a la de los EEUU (CCP, 2006) (PRB, 2006). A pesar de la rapidez de estos cambios demográficos y de las notables modificaciones en la estructura por edades que han generado, el anunciado envejecimiento de la población apenas se ha iniciado, pero cobrará fuerza en la primera mitad del siglo XXI. La población de adultos mayores de 60 años explotará de 300 mil en el censo del 2000 a cerca de 2 millones en el año 2060, con un peso en la población total de 7,6\% en el primer año (no muy diferente del $6 \%$ de 1960) y 30,6\% en el segundo (INEC \& CCP, 2002). ."

Los movimientos sociales en esta región Alajuela - San Ramón no existían como tales, por el papel tan hegemónico que tenía el poder político tradicional de los gamonales y de la misma Iglesia Católica. La educación había jugado también un papel importante, porque desde la reforma educativa de don Mauro Fernández en 1888 se había propiciado una educación de carácter positivista, en donde lo que interesaba era que los niños aprendieran a leer y a escribir y luego se integraran a las labores agrícolas de sus padres.

Anterior a la promulgación de las Garantías Sociales y el Código de Trabajo en 1943 por parte del Gobierno de Calderón Guardia, el trabajo en el campo se regulaba por la oferta y demanda de la fuerza de trabajo; esto siguió rigiendo hasta 1954, dado que existió un acuerdo con la Caja Costarricense de Seguro Social y los cafetaleros, para que estas leyes entraran a regir hasta esta fecha. Esta provocó una lucha entre los mismos campesinos por tener un trabajo fijo en las fincas de café, ocasionando entre esta misma fuerza laboral muchas rencillas personales generadas por el modelo de explotación imperante.

El peón agrícola del café tenía y tiene pocas oportunidades de mejorar su condición socioeconómica y salir de la pobreza si solo depende de un jornal o salario semanal, dado lo exiguo de la paga. No había oportunidad de alquilar tierras para sembrar otros productos como maíz o frijoles, porque el proceso de apropiación de la tierra había completado el paisaje rural con el cultivo del café. Se daba una sub utilización de la fuerza productiva porque en muy pocos casos se tenía la oportunidad de mejorar su condición de vida por la ocupación del terreno. Frente a esta situación tan angustiante, los campesinos - jornaleros de Naranjo a mediados de los años 70 fueron sintiendo la necesidad de organizarse para buscar el apoyo de instituciones como el Instituto de Tierras y Colonización (ITCO), hoy Instituto de Desarrollo Agrario, para la consecución de tierras con el objetivo de soñar con un mejor futuro para sus familias.

11. http://www.inec.go.cr/Ingresos. 14 de junio del 2009. 
Un cientista social reconocido nos apunta sobre la situación del agro en Costa Rica en los años setenta:

"En efecto en Costa Rica, la mayor parte de la población rural era mayoritariamente propietaria de tierras. Pero la extensión del monocultivo del café para la exportación produjo ciertos cambios estructurales, los cultivos alimenticios perdieron importancia, y las grandes fincas de café comenzaban a absorber las propiedades más pequeñas. Los efectos de la expansión del capitalismo monoproductor y de los cambios en la estructura de clases, han sido señalados por dos investigadores norteamericanos, quienes indican que Costa Rica "parece encontrarse en una fase de transición en la cual las propiedades campesinas están siendo asfixiadas progresivamente por las grandes fincas y corporaciones, lo cual reduce el status del pueblo de un campesinado al del peonaje.. un número creciente de personas se transforman en jornaleros y trabajan por un salario de subsistencia como peones para los grandes propietarios terratenientes". ${ }^{12}$

\section{Organización de los campesinos en Naranjo en 1975}

En febrero de 1975, se me acercaron unos jornaleros de Candelaria, que conocía muy bien porque vivíamos en el mismo distrito, para exponerme la situación que ellos vivían como peones de fincas de café y que tenían la intención de organizarse para solicitarle al ITCO unas parcelas de tierra y así soñar con un mejor futuro, y que si el suscrito les podía ayudar a organizarse. Les indiqué que no tenía experiencia de la organización de este tipo de movimientos, pero que con gusto les podía ayudar.

En ese momento era estudiante universitario en la Universidad Nacional - Heredia en la rama de historia y geografía. Las ideas sociales rondaban las aulas universitarias principalmente en la Universidad de Costa Rica y la Universidad Nacional por esos años, y era muy extraño que un estudiante universitario no tuviese una mentalidad progresista. Se había dado el derrocamiento de Salvador Allende en Chile en 1973, por parte de Augusto Pinochet, y Centro América daba signos de cambios en los gobiernos militares, principalmente en Nicaragua con la dictadura Somocista a la cual el Frente Sandinista le había dado duros golpes. Los pequeños partidos políticos de izquierda, envalentonados por estos aires de cambio en América Latina, como el Partido Vanguardia Popular, que controlaba el movimiento sindical en las zonas bananeras, el grupo FAENA, dirigido por Rodolfo Cerdas, Eduardo Doryan y otros, el Movimiento

12. Stavenhagen, Rodolfo. Las clases sociales en las sociedades agrarias. México. Siglo XXI. 1973, pág.101102, citado por Mora, Johnny. Op.cit., pág. 26. 
Revolucionario del Pueblo, el Partido Socialista, eran fruto en parte de este rico contexto social.

Tradicionalmente los sectores campesinos de esta región se plegaban en el plano electoral con aquel partido político de las simpatías de su patrón; esto era una reminiscencia del poder político que tenían los gamonales cafetaleros en la Costa Rica oligárquica. En el período de estudio, -1975- ocupaba la Presidencia de la República en el país el Lic. Daniel Oduber quien dio gran impulso al sector agrario, principalmente a los campesinos a quienes favoreció a través del Instituto de Tierras y Colonización. Esto fue otro de los factores de atracción para estos campesinos.

La crisis en el sector agrario era evidente, sin embargo; los campesinos encontraban en Daniel Oduber un gobernante preocupado por su situación socio económica. El otro partido político por el que muchos de ellos votaban en las elecciones nacionales, era el Partido Republicano Nacional. Es importante indicar que estos campesinos no tenían ni por asomo ningún interés en exigir o presionar por la vía de la confrontación la consecución de sus tierras, su formación política en estas cuestiones era escasa, no tenían una conciencia de clase definida, su sueño era convertirse en pequeños propietarios y copiar el modelo de vida que habían visto de sus patronos en el café.
$\mathrm{Al}$ respecto véase la canción popular denominada: "Nuestro futuro", que compuso don Eliseo Ovares, uno de los campesinos de Naranjo, a quién le fue adjudicada una parcela en Sonafluca. ${ }^{13}$

“... Yo vivía desilusionado, no tenía a donde sembrar /y mis fuerzas eran despojadas porque dependia de un jornal/trabajar para el rico no es bueno, no hay futuro, no lo puede haber/pero estaba el Instituto de Tierras y lo muerto volvió a renacer...."

En esta composición musical, se manifiesta la situación de explotación que vivían estos peones de café, y el anhelo de convertirse en propietarios.

¿En qué consistió la organización de estos campesinos? Ellos mismos fueron corriendo las voz con sus compañeros de trabajo en las fincas de café de Candelaria, Naranjo centro, fincas aledañas, San Antonio, San Juan, San Roque, San Rafael, San Jerónimo, San Miguel, San Juanillo, etc. De voz en voz, logramos reunir a cerca de doscientos campesinos en el Palacio Municipal de Naranjo. Otro naranjeño preocupado por la situación social que planteaban estos campesinos, se acercó al movimiento y compartimos con él las angustias y sueños de estos humildes naranjeños: nos referimos a don José Luis Ureña Ulate, quien años después llegó a ser Diputado por la

13. Ovares, Eliseo. Cantautor campesino, letra original. 
Provincia de Alajuela y representante de los cantones de Naranjo, Zarcero y Palmares. Ambos coordinamos las reuniones en el Palacio Municipal de Naranjo, dado que don José Luis Ureña era Presidente Municipal, los días sábados por la tarde.

Hicimos contacto con el ITCO, para que vinieran a Naranjo y les explicara a los campesinos el procedimiento que tenía esta institución para estos propósitos. En representación del ITCO, se apersonó don Norman Torres Morales. Don Norman era el Jefe de Selección de la Institución y tenía mucha experiencia en atender este tipo de movimientos. Supongo que para él este grupo de Naranjo era especial porque él también era oriundo de este Cantón.

Durante el año 1975, se coordinaron con el ITCO varias visitas a diversas fincas que esta Institución había comprado para estos fines. Recuerdo que fuimos a la finca la Rambla recién comprada por el ITCO en Horquetas de Sarapiquí, a Chambacú y San Joaquín de Cutris en San Carlos. El ITCO nos suministraba choferes y vehículos para las giras. Hay que hacer notar que como lo indicaba anteriormente, se notaba un interés real de la Institución por ayudar a los campesinos, no sólo porque el Presidente Oduber creía en estos programas sino porque existían figuras en el ITCO que administraban de forma excelente la institución, como era el caso en ese momento de su Presidente Ejecutivo, don José Manuel Navarrete.
El interés de los campesinos fue tal que al principio nos reuníamos 15 o 20 personas. Al final del año cuando ya se notó que había interés del ITCO por adjudicar tierras, se fueron sumando cerca de doscientos o más campesinos. Es importante destacar que un grupo de estos campesinos, los más entusiastas en un número cercano a 20, participamos en uno o quizás en el único desfile del primero de mayo que se realizara fuera de la ciudad de San José, el cual se desarrolló en la ciudad de Grecia, el 1 de mayo de 1975. De este movimiento de los campesinos Naranjeños, informaba el Periódico Pueblo:

"Luchan por su tierra: Unos 45 campesinos sin tierra, habitantes de $\mathrm{Na}$ ranjo, se vienen organizando desde hace semanas para conseguir una tierra qué trabajar. Los campesinos sin tierra, que son decenas de miles en todo el país se vienen enfrentando al creciente latifundismo que acapara la tierra y no la pone a produciro la pone muy poco.

Este grupo de naranjeños, ayudados por el Regidor José Luis Ureña y por el estudiante universitario José Luis Torres, quieren comprar una finca de trescientas manzanas en la zona de San Joaquín de Cutris, región de San Carlos. Tienen muy avanzadas las negociaciones. Ahora están en busca de un aval del ITCO para la compra de esa tierra. Tienen posibilidades de comprar otras tierras aledañas más adelante. La 
intención de los campesinos es la de construir una cooperativa de propiedad comunitaria. ${ }^{\prime 14}$

Si se revisan los periódicos de Costa Rica durante el siglo XIX y del siglo $\mathrm{XX}$, se podrá constatar que no hay referencias de movimientos sociales en Naranjo. Esta breve reseña del Semanario Pueblo, es una excepción a la regla. Las actas municipales del siglo XIX sí registran hechos de mucha trascendencia para el desarrollo del Cantón de Naranjo. ${ }^{15}$

\section{Proceso de adjudicación de las tierras a los campesinos naranjeños}

En otra visita que realizaron los personeros del ITCO se tomaron datos de cada uno de los campesinos, y se llevó a cabo en el Palacio Municipal una conversación con ellos. Don Norman Torres y compañeros, tomaban nota de la participación y preguntaban su nombre. Don Norman nos explicará luego cuál fue la metodología para escogerlos. Como dato curioso recuerdo que los que más participaron fueron escogidos para ser adjudicatarios de una parcela de tierra.

Los “dirigentes", el señor Ureña y quien escribe, no tuvimos ninguna participación en la escogencia de los mismos. Sí recuerdo que a final de ese año 1975, el señor Rivera del ITCO, estando en el autobús que conducía a Candelaria, llegó a buscarme y me dijo que tenía que conversar aspectos muy importantes sobre el grupo de campesinos de Naranjo. Nos tomamos un café, y como parte de la tertulia me hacía preguntas que le llevaran a determinar la premisa fundamental, que no se trababa de un movimiento ligado a grupos de izquierda ya que hubiera sido más complicado manejar la situación. En forma directa me indicó que no podía otorgarle una parcela de tierra a todo el grupo de Naranjo, porque tenía otros compromisos con otros grupos organizados en Chachagua de San Carlos y otras regiones del país, que podía otorgar espacio para veinticinco campesinos en Zona fluca, en Los Angeles de la Fortuna de San Carlos. Como no tenía experiencia en movimientos campesinos le dije que estaba de acuerdo; hoy pienso que era una decisión que tenía que tomarse en el seno de todo el grupo. En fin, son conjeturas porque el ITCO tenía muchos grupos de campesinos que atender en diversas regiones del país. Para los críticos del modelo de Estado intervencionista, esto refleja la forma del centralismo

14. Semanario Pueblo. Mayo de 1975, pág. 12.

15. Véase, Naranjo y su historia. Euned, 2007, pág.216. 
autoritario del Estado social demócrata de la época.

Por supuesto que hubo mucha desazón en el resto de campesinos, y no hubo más reuniones: el proceso inicial en Naranjo había concluido; vendría ahora otra etapa que era asentarse en la tierra prometida.

\section{Sonafluca ${ }^{16}$, la tierra prometida}

El 14 de junio de 1976 los 25 campesinos naranjeños fueron ubicados en sus respectivas parcelas, junto con otros campesinos de Chachagua de San Carlos. En la mayoría de los casos se fueron sólo los parceleros, porque la finca estaba cubierta de tacotales. Como es normal en estos procesos, dos o tres parceleros de Naranjo siguieron insistiendo ante el ITCO para que se les asignara una parcela, recuerdo entre ellos a Serafín Villalobos y a uno de sus hijos-Álvaro-.

El grupo de Naranjeños que fueron escogidos por el ITCO como beneficiarios en Sonafluca, de una parcela de tierra al costo de un colón, fueron los siguientes: Graciliano Núñez, Juan Benavides (+), Héctor Montero (+), Rubén Zúñiga $(+)$, Eduardo Rojas Guzmán, Eliseo Ovares Umaña, Juan Castillo,
Jacobo Arroyo, Orlando Castro Escalante, Eduardo Quesada, Álvaro Villalobos, Ezequiel Cordero (+), Alexis González, Serafín Villalobos, Horacio Murillo V., Gerardo Castro Escalante, Isidoro Rojas, Luis Jiménez, Eliécer García, Hipólito Ramírez (+), José María Céspedes, Dagoberto Arrieta, Luis Ángel Espinoza, Luis Alberto Araya.

La toma de posesión de las parcelas se hizo en forma de rifa por parte del Administrador de la finca del ITCO, de nombre Alfredo y otro asistente. En una visita que realizara dos meses después al Asentamiento Zona Fluca, pude ver la forma del trabajo de todo el grupo. El administrador los organizó de tal manera que primero debían construir una rústica casa con materiales donados por el ITCO como un zinc de asfalto, y los pilotes de la vivienda se tomaron de una reserva de bosque que quedaba de la finca. Había que construir el pozo para tener acceso al agua, y luego cada uno tenía que limpiar los carriles de su parcela que medía cinco hectáreas. Este fue un trabajo arduo, difícil, de una gran exigencia física por parte de todos los parceleros.

16. Sonafluca, se denomina así a una sociedad anónima que pertenecía a Feluco Herrera, un empresario nacional que tenía inversiones en la construcción de caminos y carreteras y en el sector agropecuario. La tradición oral hizo que la gente le denominara a la comunidad como Sonafluca. La finca se ubicaba a cuatro kilómetros hacia el oeste del Los Ángeles de la Fortuna, San Carlos, con una vista hermosa al imponente Volcán Arenal. 
Pude palpar que no tenían suficientes alimentos, tomaban mucho café y pan. Esta fase de instalación se hizo en forma colectiva, y una vez que cada uno tenía su pequeña casa con lo básico, decidieron traerse sus familias para iniciar el proceso de limpiar su tierra y alistarla para el sembradío. Hay que hacer notar que los campesinos de Naranjo venían de un clima templado, donde el clima es diferente, más frío y menos lluvioso. Los trópicos húmedos siempre han sido difíciles por las condiciones climáticas: mucha lluvia y calor. Recuerdo que el Administrador del proyecto me comentaba que eran personas muy fuertes, que tenían bien claro a qué venían y en determinado momento percibí que los hacía trabajar durante largas jornadas para cumplir las metas propuestas en un período corto de tiempo.

Los dos primeros años fueron muy duros, a pesar de que el ITCO les proporcionaba alguna ayuda de alimentos, pero esto no era suficiente para atender la gran exigencia de adaptación a este nuevo proyecto social. Algunos de estos campesinos, al notar lo duro de las jornadas y la dificultad que tenían para sembrar, optaron por regresar a Naranjo, a seguir en el trabajo de peón agrícola. A pesar de que estos campesinos eran adjudicatarios del ITCO, aún no tenían escritura de la propiedad y por tanto no eran sujetos de crédito por parte de los Bancos del Sistema Bancario
Nacional. ${ }^{17}$ No cabe duda que la estrategia de implementación que desarrolló el ITCO durante estos años, habla por sí mismo de las limitaciones y fallas de la estrategia. Existía un gran compromiso de la Institución por dotarlos de tierra, pero no existía un plan estratégico orquestado con otras instituciones para el acceso al crédito, asesoría en la siembra de determinados productos por parte del Ministerio de Agricultura, etc. El costo humano y económico resultó muy alto para estos primeros pobladores.

La respuesta del Ministerio de Educación se dio pronto, y el 7 abril de 1977, se inaugura una Escuela que empezó a trabajar en un viejo galerón que poseía la finca de don Feluco Herrera. Nos anunciaban el establecimiento de un Colegio de Secundaria para el 1 de febrero del 2007.

Con el paso de los años el Asentamiento de Sonafluca fue adquiriendo un perfil propio. Se organizaron para tener su Escuela, la plaza de fútbol, la luz eléctrica, caminos lastrados, Salón Comunal, Ermita, puentes que los comunicaran a La Fortuna y a Los Ángeles, etc. Hay que hacer notar que el desarrollo turístico de La Fortuna no había comenzado a desarrollarse sino que fue años después cuando se empezó a consolidar como uno de los sitios más visitados por el turismo nacional y extranjero.

Una vez que fueron sujetos de crédito, la mayoría de estos campesinos optaron por diversos proyectos: 
algunos tomaron el módulo lechero, sembraron yuca, papaya, plátano, etc. Como ocurre siempre en estos casos, los agricultores de estas regiones no contaban con una asesoría técnica que les indicara las ventajas y desventajas de ciertos productos, tanto en la fase de producción como de comercialización, y muchos fracasaron una y otra vez. Sin embargo, ha podido más el espíritu de sacrificio y trabajo y hoy podemos ver con orgullo que el Asentamiento de Zona fluca es una comunidad pujante que ha progresado en diversas actividades productivas.

Es importante reconocer la visión del ITCO -hoy IDA- porque ha permitido a muchas familias costarricenses sacarlas del nivel de pobreza en que se encontraban. El fomento de la pequeña propiedad, la pequeña y mediana empresa en el sector agropecuario, ha sido un mecanismo de movilidad social para muchas familias. Sonafluca es un digno ejemplo de ello; así como este Asentamiento, existen cientos de proyectos exitosos en los cuáles el IDA ha contribuido a repartir tierras a los que menos tienen. A pesar de que el IDA no acompaña en muchos casos proyectos de desarrollo para el crédito o la asesoría porque no está dentro de sus posibilidades atender en forma integral estos proyectos, sigue siendo, según nuestro criterio, una institución que debe seguir cumpliendo esta importante misión social. Costa Rica ha alcanzado niveles de desarrollo en el agro, muy superiores a otros países en vías de desarrollo; este ha sido uno de los factores que lo explican.

\section{Conclusiones}

En este artículo se ha tratado de dar al lector una visión histórica geográfica de la comunidad de Sonafluca de la Fortuna de San Carlos. Se ha intentado explicar el proceso de colonización institucional forjado a través de la lucha de varios campesinos naranjeños que soñaban con una parcela de tierra para ofrecerle un mejor futuro a sus hijos y descendientes. El relato es parcial por cuanto resume la experiencia del autor en la organización de los campesinos naranjeños a su llegada a Sonafluca en 1976, tierra que compartieron con otros labriegos que vinieron de poblados cercanos al área de estudio.

El desarrollo de la agricultura, y en menor medida de la ganadería, en unos suelos aluviales de gran

17. En el acto de celebración del 33 aniversario de la creación del asentamiento, 13 de junio del 2009, con la presencia del Concejo Municipal en pleno del Cantón de San Carlos, autoridades del IDA de la región, de Dinadeco, Coopelesca, Asociación de Desarrollo Comunal, y vecinos de la comunidad, con motivo de la inauguración de un Vado sobre el río La Fortuna y el asfaltado de dos kilómetros de carretera en el Asentamiento, los oradores del evento destacaban la calidad de las tierras y sobre todo de la gente que vino a colonizar estas tierras. 
productividad, le permitieron a sus habitantes conformar una comunidad de mucho crecimiento económico en estos treinta y tres años. Es necesario destacar que varios factores contribuyeron al éxito de este Asentamiento Campesino formado por el ITCO, hoy IDA. En primer término, el anhelo de estos campesinos que quisieron pasar a formar parte de la cadena de producción del capitalismo agrario, no desde la perspectiva de jornaleros sino como propietarios de una pequeña propiedad.

Este modelo de desarrollo que ha venido impulsado el IDA en nuestro país, con algunas limitaciones, ha sido exitoso en esta región norte. El otro factor que permitió salir de la pobreza a muchas de estas familias, ha sido la calidad de su misma gente, personas con un gran deseo de trabajar la tierra bondadosa de este valle aluvial, que con gran tesón construyeron primero sus ranchos y luego cultivaron las cinco hectáreas de tierra. Fueron muchos los fracasos con diversos cultivos, por diversas razones: plagas, problemas de mercadeo de los productos, acceso al crédito, falta de conocimiento al inicio de las particularidades de los cultivos, falta de asesoría de otras instituciones, etc.

La democracia económica del país se construye con políticas como estas, repartir tierra para producir riqueza y bienestar. En la coyuntura de esta crisis económica mundial, deben fortalecerse las políticas dirigidas al agro para favorecer la soberanía alimentaria y la exportación de los productos agropecuarios. Asimismo, esta comunidad es un ejemplo de integración a la economía del mundo a través de la educación y del turismo, y en la medida en que los descendientes de los fundadores de esta comunidad se empoderen del conocimiento tendrán un futuro más prometedor.

Como todo trabajo de historia local, este se convierte en un ensayo inicial para que se enriquezca con nuevas fuentes y testimonios de quienes día a día construyen su vida cotidiana. Esperamos que este intento ayude a fomentar la identidad local y al aprendizaje del pasado y presente de Sonafluca.

\section{Bibliografía}

Alvarado Salas, Ronulfo. Regiones y Cantones de Costa Rica. IFAM. Dirección de Gestión Municipal. San José, 2003.

Berrocal Vargas, Milena. Análisis y evaluación de la vulnerabilidad de la población de La Fortuna de San Carlos a la actividad del Volcán Arenal-Costa Rica. Tesis. Universidad de Girona, 2008.

Atlas Digital de Costa Rica. Instituto Meteorológico Nacional. San José, Costa Rica. www.imn.ac.cr/ 2004.

Chinchilla V. E. Atlas Cantonal de Costa Rica. Instituto de Fomento y Asesoría Municipal (IFAM), San José, Costa Rica, 1987.

Enríquez Solano, Francisco. Pasado y presente del Cantón de Goicoechea. EUNED, 2004. 
http://www.inec.go.cr/Ingresos. 14 de junio del 2009.

Instituto Nacional de Estadística y Censos. $I X$ Censo Nacional de la población de Costa Rica. San José, Costa Rica, 2000.

Instituto Meteorológico Nacional. San José, Costa Rica. www.imn.ac.cr/

Mora, Johnny. La vía cooperativa de desarrollo del agro. El caso de Coopronaranjo R.L. EUNA, 2007.

Rodríguez Vega, Eugenio. Costa Rica en el siglo XX. Tomo II. Vargas, Solís, Luis
P. La Economía. San José, EUNED, 2004.

Semanario Pueblo. Mayo de 1975.

Stavenhagen, Rodolfo. Las clases sociales en las sociedades agrarias. México. Siglo XXI, 1973.

Torres, José Luis. Naranjo y su historia. Euned, 2007.

UNED. Centro de planificación y programación Institucional. 2009. Mosaico Fotográfico elaborado a partir de fotografias aéreas. CARTA 2005. 